\title{
Job motivation and self-confidence for learning and development as predictors of support for change
}

\author{
Chaiporn Vithessonthi Mahasarakham University \\ Markus Schwaninger University of St. Gallen
}

\begin{abstract}
For the most part, studies on change management have attempted to determine the factors that influence employee resistance to change. The focus of the present study is to test whether job motivation and self-confidence for learning and development influence employee support for downsizing. Data were gathered from a sample of 86 teachers at one private school in Bangkok, Thailand. The analysis was carried out using multinomial ordered probit regression. The results suggest that the level of job motivation is negatively associated with the level of support for change, and that the level of self-confidence for learning and development is not associated with the level of support for change. These results are counterintuitive, and they refute our initial hypotheses.
\end{abstract}

\section{Introduction}

Greater competition, rapid technological and social changes in an emerging market economy have made efficiency improvement a crucial managerial challenge for firms to remain competitive in the marketplace. However, authors on organisational change have pointed out that managerial choices may be influenced by pressures from employees and institutional inertia (e.g., Barnett and Carroll 1995). Firms with poor performance tend to be shrinking; downsizing is then either a consequence of poor performance or one of to the options for improving performance. According to resource-based and dynamic capabilities views, it is essential for a firm to actively manage internal resources in order to sustain competitive advantages over time (Teece, Pisano and Shuen 1997). A key issue with respect to the management of firm performance is the use of downsizing. In a narrow view, downsizing has been defined as the planned reduction in a firm's personnel intended to improve the efficiency and effectiveness of a firm (Alien et al. 1995; Cascio 1993; Freeman and Cameron 1993; Wayhan and Werner 2000); in a broader perspective, downsizing has been defined as a reduction in the use of a firm's resources to improve its performance

\section{Keywords}

change management downsizing job motivation learning support for change 
(DeWitt 1998). DeWitt (1998) argues ideas that downsizing is a restructuring process, entailing three resource reduction choices: retrenchment, downscaling and down scoping. In this article, we refer to all the three kinds of downsizing.

It has been argued that the main benefits of downsizing are efficiency improvement and increased profitability. A firm that better manages its human resources so that firm-specific capabilities are created is more likely to stay competitive in the marketplace (Wright, Dunford and Snell 2001). Nevertheless, downsizing can be viewed as a breach of the psychological contract between a firm and its employees, leading to a reduction in trust in management (Mishra and Spreitzer 1998). Empirical research has found mixed results concerning the effect of downsizings on efficiency and profitability (Cascio 1993; McKinley, Sanchez and Schick 1995). One plausible explanation for this may be the influences of employees in the aftermath of downsizings. That is, a firm's downsizing success is contingent upon the attitude of employees towards change initiatives. In change management literature, employee resistance to change has been cited as the main factor derailing change initiatives (Regar et al. 1994; Kotter 1995).

Although downsizing destroys the existing social networks in a firm, it also creates a new social network that may provide new opportunities for employees who have survived (Shah 2000). Accurate knowledge of employee reaction to change is clearly essential to the selection and implementation of strategies by the firms, and employees are key firm assets, making downsizing strategies crucial. This raises important questions. What factors influence the extent to which employees support organisational change? The purpose of this study is to enhance our understanding of employee reaction to downsizing initiatives in the context of an emerging market economy where economic growth has rapidly changed the competition landscape for local firms.

This study addresses a question that is crucial for firms pursing strategic change. It focuses on the key factors that can explain observed differences in the level of support for change among the employees that face downsizing. Given that firms usually attempt to initiate a wide range of strategic actions, including downsizing, after firm performance has begun to deteriorate, it is particularly surprising that few studies (e.g., Judson 1991; Kotter 1995) have attempted to explain the differences in the level of support for change that has been observed among employees. Past research has placed considerable emphasis on various factors that can minimise employee resistance to change. Consequently, this article tries to link observed differences in the levels of support for change among employees to several factors in addition to change management models. Several researchers (Dent and Goldberg 1999; Mabin, Forgeson and Green 2001) have begun to place substantial emphasis on various factors that can influence employee reactions to change that occur in different contexts. In broad terms, employee reaction to change has been tied to a 
wide range of factors, from prevailing change process conditions to specific employee perceptions.

Given that importance of these factors, it is not surprising that Kotter (1995) suggests that managers should attempt to investigate and understand the factors that lie behind observed differences in the levels of resistance to change and support for change in order to have successful change initiatives. In this article, we therefore attempt to address this important topic in the context of downsizing in an emerging market economy that has been largely neglected by past studies. We focus exclusively on a sample of employees that can be clearly regarded as being in a downsizing situation in Thailand. We then attempt to examine and explain the differences among these employees in their support for change in spite of the firm's downsizing that might affect their job.

Research suggests that employees develop beliefs about the extent to which they are motivated to achieve their tasks and assignments (Herzberg 1968). Empirical evidence suggests that job motivation is related to a variety of work-related attitudes and outcomes (Deery et al. 1995). Two important issues requiring further attention are the relationship between job motivation and support for change on the one hand and the factors influencing the development of job motivation on the other. Likewise, research suggests that self-efficacy for development and learning influences one's performance (Maurer 2001). As such, it is of great interest to understand the effects of self-confidence for learning and development on behaviours of employees.

In this study, we propose that job motivation and self-confidence for learning and development play an important role on an employee's support for change. Under circumstances in which a firm's strategic choice such as downsizing might significantly affect employees in the firm, employees' perceptions are more likely to influence their level of support for the firm's decision. Thus, an important research issue deals with the nature of employees' perceptions during the downsizing process and how to enhance the positive effects of such perceptions while reducing the negative effects of such perceptions. This study attempts to fill a gap in current research on downsizing and change management by empirically examining the role of employees' job motivation and self-confidence for learning and development in predicting employees' support for change in the context of a downsizing endeavour pursued by a large private school in Thailand. In general, the work pattern in Thailand differs from that found in North America in that it is shaped by different values. For instance, in contrast to the United States with their universalism- and individualismoriented culture, Thailand's culture is stamped with enthusiasm for particularism and communitarianism (Cf. Hofstede, 1992: 54). Thus, these have implications on how Thai employees view the world and the people around them. In particular, they will more likely react differently to changes in the organisation than the Americans. For example, as in many Asian countries, avoiding confrontation is the norm in Thailand (Cf. Hofstede 
1992: 123f.): Traditionally, Thais seem to find it difficult to accept a direct negative response or answer. Hence, Thais tend to make excuses rather than offer a direct negative answer. Consequently, in our survey we have not used any scales including 'no' answers.

\section{Literature review and hypotheses}

\subsection{Job motivation}

Job motivation has emerged as one of the most important factors influencing a variety of work-related variables (Jalajas and Bommer, 1999; Stumpf and Hartman, 1984). Many studies in the field of change management suggest that job motivation is positively related to organisational commitment (e.g., Deery et al. 1995; Morrow 1983), work performance (Jalajas and Bommer 1999), commitment (Jalajas and Bommer 1999; Morrow 1983). In addition, Brockner, Grover, Reed and DeWitt (1992) find that perceived job enrichment has a positive and significant effect on work effort. Research on the effect of job motivation on employee absenteeism suggests that the two variables are negatively correlated (Blau 1986; Deery et al. 1995).

Recent research in the field of change management has raised interest in the extent to which employees can be motivated to perform their jobs and in the way of how firms can motivate employees (e.g., Herzberg 1968; Kanfer 1990; Vroom, 1964). When employees have high job motivation, they are likely to show better adaptive responses to any change in the organisation. Broadly speaking, managers, acting on behalf of the firm, might make decisions that affect the job motivation of employees (Korsgaard, Sapienza and Schweiger 2002), which in turn affects their attitudes and behaviours toward the decisions. If we apply the same basic rationale to how job motivation would affect absenteeism, organisational commitment and work effort, it is plausible that job motivation will be able to influence employees' support for organisational change pursued by a firm. Now, consider an organisation change from which only benefits to a firm and its employees will result. All employees must support the change in order for any of them to derive the benefits. Thus, there is an incentive for employees to try to support the firm's implementation of the change in an effort to reap private benefits. In such a situation, employees are likely to be motivated to support the change. However, employees with higher levels of job motivation are likely to provide higher levels of support for change.

Studies of job motivation support the notion that motivation is defined in relation to need strength (e.g., McClelland and Boyatzis 1984; Herzberg 1968). McClelland and Boyatzis (1984) argue that humans are motivated by need for power, achievement and affiliation. Scholars distinguish two types of motivation: intrinsic motivation refers to the relationship between employees and their job itself (Hui and Lee 2000), and is derived from within the individuals or from the activity related to the job itself (Sansone and Harackiewicz 2000); and extrinsic motivation applies to the relationship between individuals and externally administered rewards such as pay 
(Komaki, 1982). Hackman and Oldham, (1976) suggest that key characteristics that induce intrinsic motivation include task variety, task significance, task identity, and task feedback. Guerrero and Barraud-Didier (2004) suggest that job motivation can result in the high involvement in the company that will increase effectiveness and productivity. However, age can account for the degree of job motivation. In this respect, Kanfer and Ackerman (2004) argue that the attractiveness of higher levels of effort is a negative function of age, because the perceived utility of effort is expected to decline with age.

Empirically, Stumpf and Hartman (1984) find that work motivation has improved perceived work performance, and has lowered the intention to quit. Recently, Halbesleben and Bowler (2007) find that work motivation (e.g., achieving striving motivation, status striving motivation and communion striving motivation) mediates the relationship between emotional exhaustion and job performance in the sample of professional firefighters. It is logical to argue that the more job motivation a person has, the greater his/her effort to adapt to organisational change, and the greater her support for change. Employees are likely to ascertain that their job motivation and work effort are aligned; the alignment process might have some implications for their decision. For example, if employees have low job motivation, it should be relatively more difficult to increase their support for change and build trust between managers and employees in the context of downsizing. On the other hand, employees with high job motivation are more likely to be adaptive to and support downsizing, other things being equal. In sum, we hypothesise that:

H1: Higher levels of job motivation are positively associated with support for change.

\subsection{Self-confidence for learning and development}

Human resource management research has long included ideas that relate employees' self-confidence in their ability to learning and development on the one hand to work performance on the other. Research into self-confidence for learning and development suggests that humans have different beliefs about the factors responsible for what happens to them. Individuals with an internal locus of control consider what happens to them as determined by factors under their control; on the other hand, individuals with an external locus of control consider what happens to them as determined by factor outside their control (Elangovan and Xie, 1999). Self-confidence for learning and development continues to receive increasing research interest, possibly due to its importance for employees' work performance. It is however an under-researched topic, particularly when it comes to the role that self-confidence for learning and development plays in employees' reaction to organisational change.

In the literature, self-confidence is also known as self-efficacy (Maurer 2001). There has been a growing awareness in the organisational psychology 
literature that self-efficacy is a key determinant of individuals' intention and choice to pursue an activity (e.g., Bandura 1977). For instance, empirical research examining the roles of entrepreneurial self-efficacy suggests that there is a positive relationship between entrepreneurial selfefficacy and entrepreneurial intentions (Zhao, Seibert, and Hills 2005). Self-efficacy has been defined as beliefs or perceptions that one possesses the ability to complete a certain task (Foley, Kidder, and Powell 2002). In addition, Bandura (1997) suggests the notion that self-efficacy has three levels: (1) task specific self-efficacy; (2) domain self-efficacy; and (3) general self-efficacy. This categorisation however is not helpful in the context of our article which aims to explain differences in the level of support for organisational change.

In the literature we have found a distinction, which relates closer to the intention of our study: self-efficacy for development and learning and selfefficacy for performance (e.g., Maurer 2001). According to Maurer (2001), self-efficacy for development and learning refers to one's (self-)confidence in developing skills and learning new things, whereas self-efficacy for performance refers to one's confidence in performing a task for which one already possesses the skills required to perform it. We shall concentrate on the learning of new skills or advanced levels of currently possessed skills, which is crucial for competence development. One can argue that selfconfidence is conceptualised as a more global variable, whereas self-efficacy is usually conceptualised as a more local variable, implying that it is a different construct. In this respect, we do not argue for the equivalence of the two constructs, per se, rather we suggest that when we have focused on one facet of self-confidence, that is, self-confidence for learning and development, the differences between self-confidence for learning and development and self-efficacy for development and learning to become smaller. That is, self-confidence has now been conceptualised at a more local level.

Whether employees exploit potential career development is likely to depend initially on the degree to which employees believe that they possess the ability to develop skills and knowledge required to perform new tasks. Therefore, employees' self-confidence for learning and development may be an important determinant of work performance in a new work setting where a new set of skills and knowledge might be needed. In the context of organisational change where employees are likely to have perceptions of job uncertainty, employees' self-confidence for learning and development may influence employees' reaction to change.

We hypothesise that employees with high levels of self-confidence for learning and development tend to feel more comfortable with organisational change than those with low levels of self-confidence for learning and development. Because employees' self-confidence for learning and development is likely to influence the degree to which employees actually learn and develop, low levels of self-confidence for learning and development may cause employees to be afraid of potential failures to perform in a new work environment, because of their limited capability to learn new 
knowledge and/or develop new skills. Therefore, it is unlikely that they will support the change. On the other hand, employees with high levels of selfconfidence for learning and development tend to consider learning new skills resulting from organisational change as achievable. In this view, they may see the change as an opportunity to improve their career prospects rather than a threat, leading them to support the change. Based on this argumentation we present the following hypothesis.

H2: An employee's self-confidence for learning and development will be positively (negatively) related to support for change.

\section{Methodology}

\subsection{Data collection and sample}

The setting for this study was a private school in Thailand employing 108 full-time teachers at the time of the survey in 2004. Declining numbers of enrolled (both new and current) students over past few years (e.g., from approximately 200 new students per year in 1990 to around 100 new students per year in 2004) had caused the management team to make multiple efforts to improve the school's efficiency and profitability. However, the numbers of enrolled students still continued to decline each year, pressurising the management team to engage in workforce reductions. The downsizing programme was initially aimed to lay off approximately ten teachers by the start of the next academic year (i.e., 2005-2006) so as to improve the student/teacher ratio and cash flows. Teachers were informed about the downsizing decision in August 2004. At the time of the survey (during the first two weeks of September 2004), teachers did not know the full details of the downsizing programme (e.g., the involuntary nature of the workforce reductions programme).

A multiple-item survey in Thai was administered during working hours to a random sample of 100 employees at the school. The original questionnaire written in English was translated into the Thai language by one of the authors. In order to determine the clarity and the readability of the original questionnaire written in the Thai language, three other Thais had reviewed and revised the questionnaire. Then, a professional Thai-English translator back-translated the questionnaire into the English and the authors examined each item for translation error. The inspection did not find any instances where an item's meaning had significantly changed because of the translation. Survey instructions stressed that it was a survey about the planned downsizing of the school and the participation in this survey was voluntary and confidential. Ninety-one questionnaires were returned, presenting a response rate of 91 per cent. Of these, three questionnaires were excluded from the analysis because of those respondents who did not complete the main part of the questionnaires. The final sample comprised 88 cases.

According to the Office of the Primary Education Committee, Ministry of Education (Thai Ministry of Education, 2006), the number of primary 
1 Factor analysis has not been chosen because interval data were not assumed. The use of ordinal data in factor analysis may substantially alter the underlying metric scaling (Kim and Mueller, 1978). In addition, a three-point scale is likely to result in the departure from the normal distribution assumption. and secondary public school teachers in Bangkok for the academic year 2006-2007 was 12,682 teachers, 77 per cent of which held a bachelor's degree or an equivalent. Nonetheless, there was no information on the distribution of the teachers by gender and tenure. The structure of the sample was representative of both the population of the 108 teachers at this school and the population of school teachers in Bangkok and Thailand, at least with regard to the distribution of the school teachers by educational background. Eighty per cent of the sample had a bachelor's degree or an equivalent, mean age $=44.1$ years, mean position tenure $=$ 14.8 years, mean organisational tenure $=17.8$ years. In comparison with other schools in Bangkok on the basis of the number of teachers, the sample school can be considered as a large school.

Listwise deletion of missing values of the remaining sample reduced the sample size to 86 respondents (for further data analysis with two control variables: education and gender). It should be noted that the data used in this article were part of a larger survey that included 22 variables measured by 66 questionnaire items. It was a trade-off between the number of variables studied and the comprehensiveness of variable measurement in the above-mentioned survey; thus, only three items were used to measure each variable to increase the response rate. The focus of this article is on job motivation and self-confidence for learning and development because both variables seem to be closely related in terms of conceptual construct, and thus should be discussed together in this article. Other variables under study (e.g., perceived change in status, commitment, perceived organisational support, power, pride as a consequence of change, etc.) will be discussed in more details in our other papers. An overview of the survey items is given in the Appendix.

\subsection{Measures}

Unlike other studies that treated the ordinal data as the matrix data and employed a factor analysis, this study examined whether the indicators for each variable were internally consistent, that is whether it was possible to reduce the number of indicators, with the following procedures, for the use of the multinomial ordered probit model. ${ }^{1}$ We averaged across the original indicators to form an average indicator, plotted the average indicator along with the original indicators in a graph, and examined the pattern of directions of the indicators. Using this procedure, it could be observed whether the indicators for each variable followed the same pattern of directions or not. In addition to applying the graphical analyses, we also examined the Spearman correlation coefficient.

Support for change was measured using a three-item scale. Because there is no consensus on a definition of support for change, three newly developed items were used to measure the degree of behaviours that were conceived of representing employees' support for change. The three items were similar in spirit to those used by Bovey and Hede (2001). These items were measured using a five-point scale ranging from 1 (strongly disagree) 
to 5 (strongly agree). Following the procedure, the measure of support for change included two items (Cronbach's alpha $=0.70$ ).

Job motivation was measured using a three-item measure adopted from those used by Hui and Lee (2000). Respondents were asked to indicate the degree to which they agreed with these items using a five-point scale ranging from 1 (strongly disagree) to 5 (strongly agree). All three items were transformed to be used for the measure of job motivation (Cronbach's alpha $=0.81)$.

Self-confidence for learning and development was measured using a three-item measure. One item was adopted from a study by Maurer et al. (2003) reflecting employees' perceptions of their capability to learn new knowledge and develop new skills. Respondents indicated the degree to which they agreed with these items using a five-point scale ranging from 1 (strongly disagree) to 5 (strongly agree). Following the procedure, the measure of self-confidence for learning and development included all three items (Cronbach's alpha $=0.83$ ).

To control differences in education across teachers in the sample, the education variable, a categorical variable, was used to represent education and coded as follows: '0 (a degree below a bachelor level)'; '1 (a degree equivalent to a bachelor level)'; and '2 (a degree equivalent to a master level)'. To control differences in gender, the gender variable was included and coded as follows: '0 (male)' and '1 (female)'.

\subsection{Multinomial ordered probit model}

Because of the ordinal nature of the dependent variables, we therefore employed the multinomial ordered probit regression models to test the hypothesised relationships. In comparison with the ordinary regression model, the multinomial ordered probit model would be more appropriate as an analytical tool for estimation in this study because (1) the existence of a ranking of levels of a variable is taken into account, (2) it assumes that the differences between any two adjacent levels of a variable need not be the same and are unknown, and (3) it does not assume the independence of irrelevant alternative property (Alvarez and Nagler, 1998). The maximum likelihood function using the command PLUM (Polytomous Universal Model procedure) with a probit link function, in the SPSS package version 13 (see Borooah, 2002), was used to estimate parameters. It is noteworthy that the small sample size and number of parameters estimated can impose a potential estimation problem for the full model. This will be discussed in the next section.

\section{Results}

Because the sample size was relatively small and might cause the estimation problem for the multinomial ordered probit regressions, measurement scales for dependent variables and independent variables were recorded (i.e., the original scales ' 1 ' and ' 2 ' were recoded as ' 1 '; the original scales ' 3 ' was recoded as ' 2 '; and the original scales ' 4 ' and ' 5 ' were recoded as '3') to alleviate the estimation problem before the multinomial ordered 


\begin{tabular}{lccccccr}
\hline & Mean & S.D. & 1 & 2 & 3 & 4 & 5 \\
\hline 1. Support for change & 2.16 & 0.81 & .70 & & & & \\
2. Job motivation & 2.66 & 0.63 & $.26^{*}$ & .81 & & \\
3. Self-confidence for learning & 2.50 & 0.66 & $.21^{*}$ & $.38^{* *}$ & .83 & & \\
$\quad$ and development & & & & & & & \\
4. Education & 0.94 & 0.44 & .12 & .05 & .15 & - & \\
5. Gender & 0.74 & 0.44 & .11 & .06 & -.09 & -.19 & - \\
\hline
\end{tabular}

Notes: $\mathrm{N}=86$. Correlations typed in bold are significant at the 0.01 level or the 0.05 level (2-tailed).

${ }^{*} p<.05,{ }^{* *} p<.01$. Scale reliabilities (Cronbach's alpha) are shown along the diagonal.

Table 1: Descriptive statistics and Spearman correlation coefficients for the study variables.

probit regression was computed. Table 1 presents the results of the descriptive statistics, Spearman correlation coefficients and scale reliabilities (Cronbach's alpha) of the study variables. Respondents reported a mean support for change of 2.16 ( $\mathrm{SD}=0.81$ ), indicating support for change to be relative prevalent in the school. Support for change was related to all variables under study (with the exception of the education and gender variables) and showed the positive correlation with job motivation $(r=0.26$, $p<0.05)$ and the positive correlation with self-confidence for careeringrelevant learning and competence development $(r=0.21, p<0.05)$.

The results of the multinomial ordered probit models are presented in Table 2. Model 1 (Table 2) is a baseline model containing control variables. It shows that education and gender have statistically significant coefficients suggesting that teachers with higher education and female teachers are likely to have lower levels of support for change when the organisations announce downsizing. Models 2 and 3 individually add the variable of interest to test the hypotheses. Model 4 is a full model that includes all the variables of the study to check for robustness of the results.

Model 2 provides results that test Hypothesis 1, which proposes that job motivation would be positively associated with support for change. In Model 2, the coefficients for job motivation are however negative and statistically significant. These results provide no support for Hypothesis 1, suggesting that teachers with high levels of job motivation are less likely to support the change. Model 3 provides results that test Hypothesis 2, which proposes that self-confidence would be positively related to support for change. In Model 3, self-confidence for learning and development are negatively and partially predictive of support for change, suggesting that higher levels of self-confidence for learning and development increase the likelihood of having lower levels of support for change. Thus, Hypothesis 2 receives no support.

The results of Models 2 and 3 are contradictory to those of the results of Spearman correlations. That is, on the basis of the correlation coefficients, support for change was positively and significantly correlated with job 


\begin{tabular}{|c|c|c|c|c|c|c|}
\hline & & & Model 1 & Model 2 & Model 3 & Model 4 \\
\hline \multirow{4}{*}{$\begin{array}{l}\text { Dependent Variable } \\
\text { Threshold }\end{array}$} & \multirow{2}{*}{ Level 1} & Estimate & $-2.350^{* * *}$ & $-2.717^{* *}$ & $-2.553^{* *}$ & $-2.789^{* * *}$ \\
\hline & & S.E. & 0.682 & 0.720 & 0.685 & 0.725 \\
\hline & \multirow[t]{2}{*}{ Level 2} & Estimate & $-1.441^{*}$ & $-1.754^{*}$ & $-1.606^{*}$ & $-1.814^{* *}$ \\
\hline & & S.E. & 0.665 & 0.700 & 0.665 & 0.703 \\
\hline \multirow[t]{4}{*}{ Education } & \multirow[t]{2}{*}{ Level 0} & Estimate & $-1.550^{*}$ & $-1.603^{*}$ & $-1.450^{*}$ & $-1.568^{*}$ \\
\hline & & S.E. & 0.735 & 0.756 & 0.735 & 0.762 \\
\hline & \multirow[t]{2}{*}{ Level 1} & Estimate & $-1.635^{*}$ & $-1.806^{* *}$ & $-1.624^{*}$ & -1.790 \\
\hline & & S.E. & 0.662 & 0.691 & 0.663 & 0.698 \\
\hline \multirow[t]{2}{*}{ Gender } & \multirow[t]{2}{*}{ Level 0} & Estimate & $-0.534^{\dagger}$ & -0.488 & $-0.613^{*}$ & -0.537 \\
\hline & & S.E. & 0.297 & 0.303 & 0.304 & 0.309 \\
\hline \multirow[t]{4}{*}{ Job motivation } & \multirow[t]{2}{*}{ Level 1} & Estimate & & $-0.818^{\dagger}$ & & -0.541 \\
\hline & & S.E. & & 0.480 & & 0.534 \\
\hline & \multirow[t]{2}{*}{ Level 2} & Estimate & & $-0.668^{*}$ & & -0.604 \\
\hline & & S.E. & & 0.336 & & 0.345 \\
\hline \multirow{4}{*}{$\begin{array}{l}\text { Self-confidence for } \\
\text { learning and } \\
\text { development }\end{array}$} & \multirow[t]{2}{*}{ Level 1} & Estimate & & & $-0.829^{\dagger}$ & -0.555 \\
\hline & & S.E. & & & 0.455 & 0.512 \\
\hline & \multirow[t]{2}{*}{ Level 2} & Estimate & & & -0.307 & -0.159 \\
\hline & & S.E. & & & 0.276 & 0.286 \\
\hline$\chi^{2}$ & & & $8.771^{*}$ & $15.078^{*}$ & $12.700^{*}$ & $16.335^{*}$ \\
\hline
\end{tabular}

Notes: $\mathrm{N}=86$. Parameters for variables' highest level are set to zero because they are redundant. Coefficients typed in bold are significant at the 0.01 level, the 0.05 level, or the 0.10 level.

${ }^{\dagger} p<.10,{ }^{*} p<.05,{ }^{* *} p<.01$.

Table 2: Regression results of support for change.

motivation and self-confidence for learning and development. However, the correlation coefficients of 0.26 and 0.21 can be considered to be of statistical significance but of less economical significance. On the other hand, the results of Models 2 and 3 suggest that job motivation and self-confidence for change are negatively predictive of support for change. It can be seen that the results of Models 2 and 3 were only partially and statistically significant; that is, the coefficients for job motivation were significant at the 0.05 level and the 0.10 level. Hence, one can argue that the relationship between job motivation and support for change is not statistically significant at the traditional level of 0.05. Similarly, the relationship between support for change and self-confidence for learning and development was not significant at the traditional level.

Finally, examination of Model 4 suggests that the results are mixed. With all variables entered into the model, all but coefficients for control variables that were statistically significant in the earlier model become significant in the full model, suggesting that taken together, job motivation and self-confidence for learning and development are not predictive of support for change. A plausible explanation for these results is that the small sample size led to an estimation problem for the full model with the large number of parameters being estimated. In this case, the relatively clear results of Models 1, 2 and 3 overrule the results of Model 4. 


\section{Discussion and conclusion}

Both hypotheses are therewith provisionally refuted, which is surprising in the light of the assumptions made at the outset. The aim of this article is to relate an employee's job motivation and self-confidence for learning and development to the employee's support for organisational change. At the most basic levels, the findings in respect of job motivation extend current research on the importance of developing job motivation by linking employees' job motivation to the aim of a firm's downsizing endeavours: support for change in order to improve the efficiency and profitability of the firm. In doing so, we support Stumpf and Hartmann's (1984) suggestion that work motivation is the driver of work performance. Firms invest in human resource system with the hope that this investment will translate into higher levels of job motivation, more advantageous human capitals, and thus better work performance. In the context of downsizing, firms would expect to receive support for change from employees with high levels of job motivation. The negative and significant impact of job motivation in Model 2 suggest that this does not indeed occur. Rather than being supportive of change in the context of downsizing, we found that job motivation had a negative effect on teachers' support for change. The results are inconsistent with other studies (e.g., Narayan et al. 2007). Narayan et al. (2007) find that people who were motivated to learn demonstrated higher levels of readiness to change in a United States sample of 127 driving under influence offenders. The findings suggest that employees with high levels of job motivation do in practice provide relatively low levels of support for change, at least when they are confronted with downsizing. One plausible explanation for this effect is that one may be afraid of being seen as providing support for a plan that will result in a potential layoff of his/her colleagues and that one may be indeed required to provide moral support to those who will be affected by the downsizing by means of providing no support to the downsizing. From these data one might conclude that the human resource system, which had increased job motivation of the employees, had failed in that it had not been able to generate the employees' support for the downsizing.

The findings pertaining to self-confidence for learning and development suggest that this may not help a firm with its downsizing. That is, employees with self-confidence for learning and development tend to provide low levels of support for change when a firm introduces downsizing. The results suggest that a somewhat complex process governs the relationship between self-confidence for learning and development and a variety of variables that represent employees' behaviour. When employees have self-confidence for learning and development, this facilitates their actual learning and development in response to the requirement of new work demand. This benefits the firm. However, when a firm introduces organisational change (e.g., downsizing) to improve firm performance, employees with high self-confidence are unlikely to provide support for change. 
The results suggest that it will be easier to realise a downsizing programme, if the workforce consists of employees with low levels of selfconfidence for learning and development. One may conjecture that this level of self-confidence will lead to a more effective change programme, with improvements of the organisation's efficiency and profit. Even though such an assumption would require additional empirical evidence, one can cogently assume that employee support - ceteris paribus - leads to downsizing success.

The different characteristics of employees required in different contexts are problematic for firms. On the one hand, one may argue that employees with self-confidence for learning and development are strategic assets that potentially help a firm sustain competitive advantage over time (Wright et al. 2001), because these employees are more likely to be capable of significantly improving work performance and adapting to new job requirements. On the other hand, based on the findings of this study, employees with high self-confidence for learning and development are less likely to provide support for change; thus, a firm that introduces downsizing is less likely to receive employee support for change, reducing the probability of downsizing success. Taken together, the results about education and selfconfidence for learning and development results suggest that when a firm initiates changes in the organisation, it should expect that employees with high education and self-confidence for learning and development tend to provide low levels of support. One plausible explanation for the results is that teachers with high education and self-confidence for learning and development hold beliefs that there are other existing job opportunities available to them outside the organisation; thus, they might see no incentives to support downsizing pursued by the school.

A number of limitations to this study require attention. First, as discussed earlier, the small sample size led to an estimation problem for the full model, thereby making coefficients for explanatory variables in the full model insignificant. Second, self-reported data in this study made it difficult to separate method variance from true score variance. It is possible that method variance bolstered or weakened the magnitude of relationships between predictors and outcomes. To reduce the possibility of mono-method bias, future studies should aim to incorporate other methods than relying on subjects' self-reports. For instance, future research should assess the extent to which direct observation of employees can be used to measure the employees' job motivation and support for change. Last but not least, this study is exclusively based on cross-sectional data; hence, the causal inferences regarding predictor/outcome relationships could not be determined. Longitudinal designs in future studies would enable true causal inferences.

This said, there is much more work to be done. An obvious extension of this line of research would be to compare data from this study with data from other downsizing plans and organisational contexts. For example, we would hypothesise that job motivation would decrease resistance to a downsizing. The logic is that an employee may be morally obliged to not 
support the downsizing that will negatively affect his or her colleagues. As suggested before, future research should look more closely at the dynamic interplay between job motivation and self-confidence for learning and development in order to tease out more subtle effects on the development of human resource potential. More specifically, job motivation and selfconfidence for learning and development not only improve work performance but also decrease support for change. Are there differences in the effects of job motivation on support for change in the context of asset expansion versus downsizing programmes? At the same time, it should be examined whether the different types of data analysis methods significantly influence the outcomes of the study. This is particularly important because scholars in management studies tend to adopt the ordinary regression analysis in their study of dependent variables that are measured on ordinal scale. McKelvey and Zavoina (1975), for example, suggest that using regression models that do not appropriately account for the nature of ordinal data may provide misleading results. Therefore, we might want to revisit our analysis in order to examine the extent to which employees' job motivation and self-confidence in learning and development are likely to have negative effects on employees' attitudes and behaviours in other contexts. Finally, longer-term implications of job motivation and selfconfidence for learning and development should be studied. This should be set alongside further work on the processes that create employees' job motivation and self-confidence for learning and development. This should lead to a more comprehensive account of the processes that govern employee reaction to a variety of organisational initiatives.

\section{Appendix: Questionnaire survey items}

Support for change

1. I agree with the organization's decision to make this change.

2. This change is acceptable to me.

3. I certainly comply with this change.

Job motivation

1. I take pride in doing my job as well as I can.

2. I try to think of ways of doing my job effectively.

3. I feel a sense of personal satisfaction when I do my job well.

Self-confidence for learning and development

1. I am very confident at learning and developing new skills relevant to my job.

2. I know I am very capable of keeping up with new techniques and knowledge required for my job.

3. I can develop my career-relevant skills.

\section{Works cited}

Alien, T.D., Freeman, D.M., Reizenstein, R.C. and Rentz, J.O. (1995), 'Just Another Transition? Examining Survivor's Attitudes Over Time', Academy of Management Journal (Best Papers Proceedings), pp. 78-82.

Alvarez, R.M. and Nagler, J. (1998), 'When Politics and Models Collide: Estimating Models of Multiparty Elections', American Journal of Political Science, 42: 1, pp. 55-96. 
Bandura, A. (1977), 'Self-Efficacy: Toward a Unifying Theory of Behavioral Change', Psychological Review, 84: 2, pp. 191-215.

Bandura, A. (1997), Self-Efficacy: The Exercise of Control, New York: W.H. Freeman.

Barnett, W.P. and Carroll, G.R. (1995), 'Modeling Internal Organizational Change', American Review of Psychology, 21: 1, pp. 217-236.

Blau, G. (1986), 'Job Involvement and Organizational Commitment as Interactive Predictors of Tardiness and Absenteeism', Journal of Management, 12: 4, pp. 577-584.

Borooah, V.K. (2002), Logit and Probit: Ordered and Multinomial Models, Thousand Oaks, CA: Sage.

Bovey, W.H. and Hede, A. (2001), 'Resistance to Organisational Change: The Role of Defence Mechanisms', Journal of Managerial Psychology, 16: 7/8, pp. 534-548.

Brockner, J., Grover, S., Reed, T.F. and DeWitt, R.L. (1992), 'Layoffs, Job Insecurity, and Survivors' Work Effort: Evidence of an Inverted-U Relationship', Academy of Management Journal, 35: 2, pp. 413-425.

Cascio, W.F. (1993), 'Downsizing: What Do We Know? What Have We Learned?', Academy of Management Executive, 7: 1, pp. 95-104.

Deery, S.J., Erwin, P.J., Iverson, R.D. and Ambrose, M.L. (1995), 'The Determinants of Absenteeism: Evidence from Australian Blue-Collar Employees', International Journal of Human Resource Management, 6: 4, pp. 825-848.

Dent, E.B. and Goldberg, S.G. (1999), 'Challenging 'Resistance to Change”, The Journal of Applied Behavioral Science, 35: 1, pp. 25-41.

DeWitt, R.L. (1998), 'Firm, Industry, and Strategy Influences on Choice of Downsizing Approach', Strategic Management Journal, 19: 1, pp. 59-79.

Elangovan, A.R and Xie, J.L. (1999), 'Effects of Perceived Power of Supervisor on Subordinate Stress and Motivation: The Moderating Role of Subordinate Characteristics', Journal of Organizational Behavior, 20: 3, pp. 359-373.

Foley, S., Kidder, D.L. and Powell, G.N. (2002), 'The Perceived Glass Ceiling and Justice Perceptions: An Investigation of Hispanic Law Associates', Journal of Management, 28: 4, pp. 471-496.

Freeman, S.J. and Cameron, K.S. (1993), 'Organizational Downsizing: A Convergence and Reorientation Framework', Organization Science, 4: 1, pp. 10-28.

Guerrero, S. and Barraud-Didier, V. (2004), 'High-Involvement Practices and Performance of French Firms', International Journal of Human Resource Management, 15: 8, pp. 1408-1423.

Halbesleben, J.R.B. and Bowler, W.M. (2007), 'Emotional Exhaustion and Job Performance: The Mediating Role of Motivation', Journal of Applied Psychology, 92: 1, pp. 93-106.

Hackman, J.R. and Oldham, G.R. (1976), 'Motivation through the Design of Work: Test of a Theory', Organizational Behavior and Human Performance, 16: 2, pp. 250-279.

Herzberg, F. (1968), 'One More Time: How Do You Motivate Employees?', Harvard Business Review, 46: 1, pp. 53-62.

Hofstede, G. (1992), Cultures and Organizations. Software of the Mind, London: McGraw-Hill.

Hui, C. and Lee, C. (2000), 'Moderating Effects of Organization-Based Self-Esteem on Organizational Uncertainty: Employee Response Relationships', Journal of Management, 26: 2, pp. 215-232.

Jalajas, D.S. and Bommer, M. (1999), 'The Influence of Job Motivation Versus Downsizing on Individual Behavior', Human Resource Development Quarterly, 10: 4, pp. 329-341. 
Judson, A. (1991), Changing Behavior in Organizations: Minimizing Resistance to Change. Cambridge, MA: Basil Blackwell.

Kanfer, R. (1990), 'Motivation Theory and Industrial and Organizational Psychology', in M.D. Dunnette and L.M. Hough (eds.), Handbook of Industrial and Organizational Psychology, Palo Alto, CA: Consulting Psychologists Press, 1, pp. 75-170.

Kanfer, R. and Ackerman, P.L. (2004), Aging, Adult Development, and Work Motivation', Academy of Management Review, 29: 3, pp. 440-458.

Kim, J.-O. and Mueller, C.W. (1978), 'Factor Analysis: Statistical Methods and Practical Issues', Thousand Oaks, CA: Sage Publications.

Komaki, J. (1982), 'Managerial Effectiveness: Potential Contributions of the Behavioral Approach', Journal of Organizational Behavior Management, 3: 3, pp. 71-83.

Korsgaard, M.A., Sapienza, H.J. and Schweiger, D.M. (2002), 'Beaten Before Begun: The Role of Procedural Justice in Planning Change', Journal of Management, 28: 4, pp. 497-516.

Kotter, J. (1995), 'Leading Change: Why Transformation Efforts Fail', Harvard Business Review, 73: 2, pp. 59-67.

Mabin, J.V., Forgeson, S. and Green, L. (2001), 'Harnessing Resistance: Using the Theory of Constraints to Assist Change Management', Journal of European Industrial Training, 25: 2-4, pp. 168-191.

Maurer, T. (2001), 'Career-Relevant Learning and Development, Worker Age, and Beliefs About Self-Efficacy for Development', Journal of Management, 27: 2, pp. 123-140.

Maurer, T.J., Wrenn, K.A., Pierce, H.R., Tross, S.A. and Collins, W.C. (2003), 'Beliefs About 'Improvability' of Career-Relevant Skills, Relevance to Job/Task Analysis, Competency Modelling, and Learning Organization', Journal of Organizational Behavior, 24: 1, pp. 107-131.

McClelland, D.C. and Boyatzis, R. (1984), 'Leadership Motive Pattern and LongTerm Success in Management', in C.D. Spielberger (ed.), Motives, Personality, and Society: Selected Papers. New York: Praeger.

McKelvey, R.D. and Zavoina, W. (1975), 'A Statistical Model for the Analysis of Ordinal Level of Dependent Variables', Journal of Mathematical Sociology, 4, pp. 103-120.

McKinley, W., Sanchez, C.M. and Schick, A.G. (1995), 'Organizational Downsizing: Constraining, Cloning, Learning', Academy of management Executive, 9: 3, pp. 32-44.

Mishra, A.K. and Spreitzer, G.M. (1998), 'Explaining How Survivors Respond to Downsizing: The Roles of Trust, Employment, Justice, and Work Redesign', Academy of Management Review, 23: 3, pp. 567-589.

Morrow, P.C. (1983), 'Concept Redundancy in Organizational Research: The Case of Work Commitment', Academy of Management Review, 8: 3, pp. 486-500.

Narayan, A., Steele-Johnson, D., Delgado, K.M. and Cole, P.A. (2007), 'Differential Effects of Pretraining Influences on Readiness to Change', The Journal of Psychology, 141: 1, pp. 47-60.

Regar, R.K., Mullane, J.V., Gustafson, L.T. and DeMarie, S.M. (1994), 'Creating Earthquakes to Change Organizational Mindsets', Academy of Management Executive, 8: 4, pp. 31-46.

Sansone, C. and Harackiewicz, J.M. (2000), Intrinsic and Extrinsic Motivation: The Search for Optimal Motivation and Performance. San Diego, CA: Academic Press.

Shah, P.P. (2000), 'Network Destruction: The Structural Implications of Downsizing', Academy of Management Journal, 43: 1, pp. 101-112. 
Stumpf, S.A. and Hartman, K. (1984), 'Individual Exploration to Organizational Commitment or Withdrawal', Academy of Management Journal, 27: 2, pp. 308-329.

Teece, D.J., Pisano, G. and Shuen, A.A. (1997), 'Dynamic Capabilities and Strategic Management', Strategic Management Journal, 18: 7, pp. 504-534.

Thai Ministry of Education (2006), Education Statistics: 2006, Bangkok, Thailand: Thai Ministry of Education Printing Office.

Vroom, V.H. (1964), Work and Motivation, New York: Wiley.

Wayhan, V.B. and Werner, S. (2000), 'The Impact of Workforce Reductions of Financial Performance: A Longitudinal Perspective', Journal of Management, 26 : 2, pp. 341-363.

Wright, P.M., Dunford, B.B. and Snell, S.A. (2001), 'Human Resources and the Resource-Based View of the Firm', Journal of Management, 27: 6, pp. 701-721.

Zhao, H., Seibert, S.E. and Hills, G.E. (2005), 'The Mediating Role of Self-Efficacy in the Development of Entrepreneurial Intentions', Journal of Applied Psychology, 90: 6, pp. 1265-1272.

\section{Suggested citation}

Vithessonthi, C., \& Schwaninger, M. (2008), 'Job motivation and self-confidence for learning and development as predictors of support for change', Journal of Organisational Transformation and Social Change 5: 2, pp. 141-157, doi: 10.1386/ jots.5.2.141/1

\section{Contributor details}

Chaiporn Vithessonthi is a visiting lecturer in the Faculty of Accountancy and Management at Mahasarakham University. He received his doctorate degree from the University of St. Gallen, Switzerland. His research interests include international management, corporate finance and competitive strategy. Contact: Chaiporn Vithessonthi, Faculty of Accountancy and Management, Mahasarakham University, Kantarawichai, Mahasarakham 44150, Thailand.

E-mail: chaiporn.vithessonthi@gmx.ch

Markus Schwaninger is a Professor of Management at the University of St. Gallen, Switzerland. His research focuses on issues of general management, namely strategy and organisational transformation. Methodologically, his works are oriented towards innovative approaches to dealing with complexity. Contact: Markus Schwaninger, Institute of Management, University of St. Gallen, Dufourstrasse 40a, CH-9000 St Gallen, Switzerland.

E-mail: markus.schwaninger@unisg.ch 
Copyright of Journal of Organisational Transformation \& Social Change is the property of Intellect Ltd. and its content may not be copied or emailed to multiple sites or posted to a listserv without the copyright holder's express written permission. However, users may print, download, or email articles for individual use. 